\title{
The social side of shadow IT and its impacts: investigating the relationship with social influence and social presence.
}

\author{
Gabriela Labres Mallmann \\ UFRGS \\ gabilmallmann@gmail.com
}

\author{
Antônio Carlos Gastaud Maçada \\ UFRGS \\ acgmacada@ea.ufrgs.b
}

\author{
Gustavo P. Z. Montesdioca \\ UFRGS \\ gustavopercio@gmail.com
}

\begin{abstract}
The use of shadow IT within organizations may offer an interesting context to analyze individual behavior in the contemporary society. Considering that social factors profoundly influence user behavior, we aim to investigate the relationship of perceived social influence and perceived social presence on shadow IT usage and its impacts based on the assumption that social factors influence individuals towards the use of shadow IT. We performed a survey among employees from different companies. The results show that shadow IT usage has a strong positive relationship with the social factors investigated here, which positively impacts employee's work performance. Our findings suggest that shadow IT is a collective solution used and socially recognized by workgroups. In addition, we found that shadow IT can lead to optimized communication and collaboration among employees, teams or departments.
\end{abstract}

\section{Introduction}

The pervasiveness of technology in our private and professional lives is changing how we communicate, interact, and socially behave [1]. These changes are affecting individuals, organizations, and the society as a whole. Technology is widely available nowadays and individuals are able to autonomously find new solutions and exploit the functionalities it provides, including in the workplace [2]. Within this context, the use of unauthorized technology, called shadow IT, is attracting attention as an organizational phenomenon that challenges the traditional attitude towards managing technology.

Shadow IT usage is defined as the voluntary use of any IT resource that violates IT norms at workplace, as a reaction to perceived situational constraints, with the objective of improving work performance [3]. Shadow IT usage is increasing within organizations. According to Gartner research
[4], IT departments will make fewer technology decisions, while individual business units will increasingly select technology for their teams, with $38 \%$ of technology purchases being managed, defined and controlled by business leaders.

The use of shadow IT in organizations, then, may offer an interesting context to analyze individual behavior [5]. Given the technology induced changes in the way we communicate and interact with others, as well as the organizational changes in how technology is managed, social factors such as social influence and social presence may contribute toward explaining individual behavior regarding shadow IT usage. Social influence seeks to explain the changes that occur to an individual resulting from interaction with others, while social presence aims to explain how users select inter-relational channels.

Social factors profoundly influence user behavior. Previous studies have shown social influence impacts user behavior, since interaction with another person or with a group may change the thoughts, feelings, or behavior of an individual $[6 ; 7]$. Current IS literature suggests IT departments have less influence on the choice of technology used by employees to perform their work [6], suggesting new and unrevealed social dynamics are at play in the shadow IT context.

Related to social interactions, the concept of social presence is relevant at this time when there is a growing dependence on the use of technology to interact with others, especially among digital natives [1]. Previous research suggests several technologies identified as shadow IT are communication and content sharing applications, such Google Drive, Dropbox and Skype that are used to communicate and interact with co-workers [8; 9]. Accordingly, Shumarova and Swatman [10] suggest that in a contemporary teamwork environment, the primary performance requirement within a workgroup is "speed", including to communicate. Thereby, employees are demanding instantaneous communication, easy content update and dissemination when performing their tasks in order to maintain high individual performance. 
Taking into account a perspective based on social factors related to user behavior, we asked: what are the relationship of social influence and social presence on shadow IT usage and what are their impacts on the individual? Numerous empirical studies have found that social factors positively influence an individual's IT usage [7; 11]. In our study, we aim to investigate the relationship of perceived social influence and perceived social presence on shadow IT usage and its impacts on the individual based on the assumption that social factors influence individuals towards the use of shadow IT, which cause individual impacts to employee's work performance [12].

Shadow IT emerges at the employee level [13]. Then, understanding the individual behavior related to the use of technology is central to manage shadow IT $[12 ; 14]$. Moreover, it is crucial to examine the motivations and the consequences of shadow IT for individuals [15]. Managers should also understand the causes and consequences of shadow IT usage in order to deal with this challenge [5; 15]. Similarly, taking into account the importance of individual system usage for organizational success [16], examining why individuals are using a technology also regarding the consequences provided by this technology can be fruitful to understand individual behavior.

We performed a survey among 286 employees from different companies. The results here indicate that social factors play an essential role in the individual behavior toward shadow IT usage. Social influence and social presence are both antecedents of shadow IT usage, driving individuals and workgroups to use shadow IT within organizations. Furthermore, these social factors explain to some extent the individual impacts of shadow IT usage on employee work performance. Therefore, this study contributes to expanding knowledge on shadow IT at the individual level by performing an empirical investigation on the antecedents and consequences of employees' shadow IT usage.

The paper is organized as follow. The next section provides the reader with the theoretical background of shadow IT, social influence and social presence. Next, we develop the hypotheses of our research mode. The following methodology section describes the applied research method. The result section presents the statistical analysis that is discussed in the discussion section. The final part of the paper depicts the conclusions, limitations and further research.

\section{Literature review}

\subsection{Shadow IT}

Shadow IT is defined as any IT solution used by employees to perform their work tasks with no formal approval or support from the company's IT department $[8 ; 13 ; 15 ; 17]$. Recent studies $[3 ; 12]$ have addressed shadow IT from an individual level perspective, investigating the behavioral aspects related to the use of shadow IT (e.g., motivations or antecedents) from the employee's perspective. In line with those studies, we follow the definition of shadow IT usage proposed by Haag and Eckhardt [3], which states that shadow IT usage is "the voluntary usage of any IT resource violating injunctive IT norms at the workplace as reaction to perceived situational constraints with the intent to enhance the work performance, but not to harm the organization". Thus, shadow IT refers to the unauthorized technology, while the term shadow IT usage refers to the individual behavior of using shadow IT.

To a better definition of shadow IT, Haag and Eckhardt [15] highlight that shadow IT distinguishes from closely related concepts such as workaround, bring-your-own (BYO), and IT consumerization. Although those concepts carry some similarities, there are crucial differences that "characterize and justify shadow IT as a unique and relevant concept worthy of future investigation" [15]. Workaround is a broader concept that encompasses other instances, including non-IT-devices and shadow IT and it can be classified as deviant work behavior. In turn, BYOD cannot be considered a deviant behavior because it is a policy that allows employees to bring and use personal devices at work [15].

The use of shadow IT has been considered one way to fill the gap between user needs and the solutions provided by IT departments $[13 ; 17 ; 18]$ because IT managers can understand users' needs and expectations by identifying shadow IT employees are using. Consequently, the use of Shadow IT is paradoxical in nature as it represents a voluntary action that often violates company and IT department norms but without any malicious intentions.

Shadow IT exists separately from organizational IT solutions, being a form of decentralized computing implemented by individuals, workgroups or whole business units $[14 ; 19]$. Depending on their business needs, different units and individuals implement a wide range of solutions, using a variety of unauthorized technologies [20]. Therefore, the use of shadow IT can encompass a variety of possibilities, since shadow IT can be a hardware, software, or any other solution, such as a ready-made spreadsheet, cloud services, a self-developed 
application, instant message application, collaborative tools, etc. $[8 ; 9 ; 21]$.

\subsection{Social influence}

Social Influence (SI) is defined as the degree to which an individual perceives that important people believe that he/she should use a new system [24]. For Ogara, Koh and Prybutok [25], social influence is a change in thoughts, feelings, attitudes or behavior of an individual that results from the interaction with another person or with a group. Individuals are more likely to perform a behavior when they believe that certain people think they should perform this behavior, encouraging them to satisfy the expectations of those referents [26]. Thereby, social influence can be seen as a direct determinant of user behavior $[7 ; 11 ; 27]$.

Subjective Norm (SN) is the dominant conceptualization of social influence $[7 ; 28]$. In the information systems research, investigation of social influence is linked mostly to the perception of subjective norms and/or cultures and their effect on the adoption and use of technology by individuals [6]. In line with previous research [24], we used in our study subjective norms to analyze and measure social influence.

\subsection{Social presence}

The term social presence is defined as a "feeling of being with the other in a mediated environment" [29]. The construct is used specifically to mean interactions in environments mediated by technology [30]. The term has its origin in the Theory of Social Presence proposed by Short, Williams and Christie [31] to explain how users select communication channels. The theory suggests different media have different capabilities to transmit signals that create awareness of other social actors in the user [32].

Thus, individuals may perceive technologies as providing various levels of social presence. In that sense, social presence is conceptualized as the degree, along a continuum, of how sociable or unsociable, sensitive or insensitive, personal or impersonal a particular technology may be [25]. Hence, users may decide to use the media available to change the sense of social presence to perform a wide range of activities, such as meeting someone, exchanging information and points of view, generating ideas, so on so forth [30].

It is important to note that social presence is social, that is, based on mutual interactions [29]. The mutuality of feelings and perceptions regarding the sense of social presence is central in interactions mediated by technology.

\section{Development of hypotheses}

The usage context here is the use of unauthorized information technology to perform work tasks inside organizations. Therefore, shadow IT is the target technology for this study. User behavior, in general, differs from shadow IT user behavior because the last one is a deviant behavior, that is, when using shadow IT in the workplace employees voluntarily deviate from IS policies [3].

Previous studies suggest that shadow IT can be used by one individual or a group of individuals, which means that the use of shadow IT disseminates among employees [13; 14]. Different from the traditional IS usage (e.g., mandatory technology), shadow IT is adopted and used by employees and workgroups with no participation of IT department, which configures a different social dynamics within organizations.

Extant studies also indicate that shadow IT is frequently used to communicate and collaborate with co-workers, clients and external partners [8; 9]. Moreover, the dependence on technology to interact with people is increasing [1], which is changing the way we socially interact and bringing several consequences related to those changes. Within this context, the social influence and social presence constructs were used as a theoretical lens to investigate the use of shadow IT among employees to capture the social dynamics in the context of unauthorized technology usage. We argue thus that social influence and social presence can be antecedents of shadow IT usage and aid to explain some consequences of its usage for employees.

Building on the above conceptualization, we now focus on our research model. We develop our model and hypotheses as displayed in Figure 1, which we expand upon below.

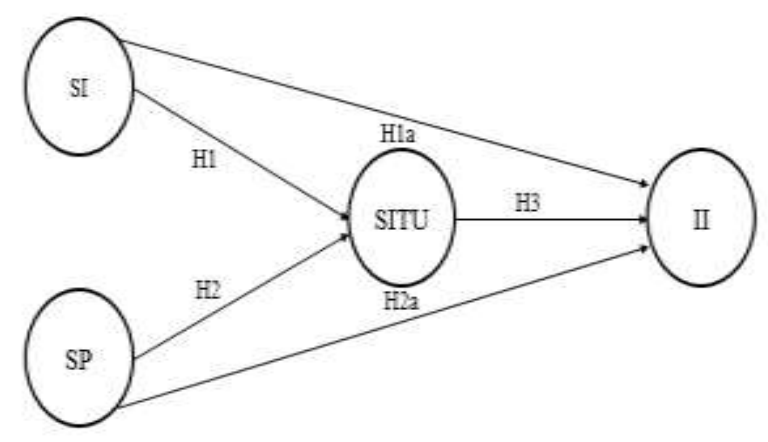

Figure 1. Research model 


\subsection{Social influence and shadow IT usage}

As discussed in the literature review, changes in behavior due to interaction with others, especially people considered important or close, can influence individual's behavior and choices [25]. The current IS literature is suggesting that the IT department is losing the influence on the choice of technology used by employees to perform their work [6]. This influence, then, may be coming from people such as co-workers, friends or even the head of the business unit.

The business units are in a better position now to create new digital streams for themselves and engaging with digital tools more intensely than ever and, consequently, it is becoming increasingly difficult for IT managers to govern the growing variety of IT systems within companies [22]. In this context, next generation of digital companies is being driven by a new wave of business managers and employees who do not need technology to be contextualized by an IT department. Thus, the employee's choice regarding the technology to perform the work tasks is being influenced by workmates, friends or the business unit boss that indicate a solution. Moreover, business units are gaining their own budget to implement IT solution without the traditional process of consulting the IT department, which is causing individual impacts to employee's work consequently.

Thereby, we theorized that, in the shadow IT context, employees may be influenced by immediate referents (e.g., peers and superiors) toward the use of shadow IT. The influence from subordinates and IT department were not considered because 1) most of IT users that use shadow IT do not have subordinates in the hierarchy and 2) shadow IT is regarding the use of unauthorized technology, then it is a deviant work behavior and not related to the IT department influence. Consistent with the above arguments, we hypothesize:

H1: Perceived social influence is positively related to shadow IT usage.

Previous research suggests that social influence is positively related to user satisfaction [25], which increase the use of technology and cause individual impacts such as greater work performance [16]. Social influence also can be related to a collective belief among the users of a team or department that certain IT is cutting-edge regarding innovation, efficiency, and practicality [33], driving employees to use that technology. Then, we hypothesize:
H1a: Shadow IT usage mediate the relationship between social influence and individual impacts.

\subsection{Social presence and shadow IT usage}

Literature suggests that face-to-face interaction provides the highest sense of social presence, followed by video, audio, and text [30; 34]. People interactions are increasingly being mediated by technology not only because of preferences but also by necessity, including at workplace. Consequently, employees are using technology that provides to them the social presence required by the task they need to accomplish [34]. Whether the IT department is not providing the suitable tool, the employees will autonomously find out and use a technology that meets their preferences and needs to perform the work tasks.

Previous studies have identified that employees frequently use unauthorized technology to communicate and collaborate at work [8;10], as well as to share information and knowledge among workmates $[9 ; 35]$. Solutions that provide instantaneous communications such as Skype, Whatsapp, Google Drive and Dropbox often are used within companies with no permission and support of IT department $[8 ; 9 ; 18]$. Considering the above arguments, we hypothesize:

$\mathrm{H} 2$ : Perceived social presence is positively related to shadow IT usage.

The literature, then, suggests that the individual has the objective of enhancing the sense of social presence, which is influencing the use of shadow IT to perform the work tasks. Similarly, social presence is shown to be positively related, directly andlor indirectly, to task performance [30; 34].

H2a: Shadow IT usage mediate the relationship between social presence and individual impacts.

\subsection{Individual impacts using shadow IT}

Literature on shadow IT has discussed several negative and positive consequences of shadow IT usage to individual and organizations. Regarding the individual level, previous studies have discovered individual impacts promoted by shadow IT usage that affects employee's work performance, such as improvement at productivity and better communication and collaboration among workers [8; 9; 10; 36]. Haag, Eckhardt, and Bozoyan [12], for instance, found that Shadow IT users are significantly more intrinsically motivated and enthusiastic to develop new ideas for enhancing the existing 
technology and processes to solve tasks in a better manner. Thereby, we consider that the use shadow IT can provide positive consequences to users like improve their task performance [3]. Potential negative consequences of shadow IT usage are out of the scope of this research. We hypothesized then:

H3: Shadow IT usage is positively related to individual impacts on employee's work performance.

Table 1 provides a summary of the literature review on the main constructs. We conduct the remainder of the study based on the definitions and elements presented below.

\section{Table 1. Summary of the literature review on} the main constructs

\begin{tabular}{|c|c|c|c|}
\hline Construct & Definition & Elements & Authors \\
\hline $\begin{array}{l}\text { Shadow IT } \\
\text { Usage } \\
\text { (SITU) }\end{array}$ & $\begin{array}{l}\text { The voluntary } \\
\text { use of any IT } \\
\text { resource that } \\
\text { violates IT } \\
\text { norms at the } \\
\text { workplace with } \\
\text { the objective to } \\
\text { enhance the } \\
\text { work } \\
\text { performance. }\end{array}$ & $\begin{array}{l}\text { Unauthorize } \\
\text { d cloud } \\
\text { services, } \\
\text { self- } \\
\text { developed } \\
\text { solutions, } \\
\text { self-installed } \\
\text { applications } \\
\text { and self- } \\
\text { acquired } \\
\text { devices. }\end{array}$ & $\begin{array}{l}{[3 ; 8 ; 13 ;} \\
18 ; 19 ; \\
22 ; 23]\end{array}$ \\
\hline $\begin{array}{l}\text { Individual } \\
\text { Impacts (II) }\end{array}$ & $\begin{array}{l}\text { Individual } \\
\text { consequences } \\
\text { promoted by } \\
\text { shadow IT } \\
\text { usage that } \\
\text { affects } \\
\text { employee's } \\
\text { work } \\
\text { performance. }\end{array}$ & $\begin{array}{l}\text { Task } \\
\text { performance, } \\
\text { productivity, } \\
\text { collaboration, } \\
\text { information } \\
\text { sharing and } \\
\text { problem- } \\
\text { solving. }\end{array}$ & $\begin{array}{l}{[8 ; 10 ;} \\
12 ; 13 ; \\
22]\end{array}$ \\
\hline $\begin{array}{l}\text { Perceived } \\
\text { Social } \\
\text { Influence } \\
\text { (SI) }\end{array}$ & $\begin{array}{l}\text { The degree to } \\
\text { which an } \\
\text { individual } \\
\text { perceives that } \\
\text { important } \\
\text { people believe } \\
\text { that he/she } \\
\text { should engage } \\
\text { in a behavior. }\end{array}$ & $\begin{array}{l}\text { Influence of } \\
\text { employee's } \\
\text { superior and } \\
\text { peer } \\
\text { influence. }\end{array}$ & $\begin{array}{l}{[7 ; 24 ;} \\
25 ; 37]\end{array}$ \\
\hline $\begin{array}{l}\text { Perceived } \\
\text { Social } \\
\text { Presence } \\
\text { (SP) }\end{array}$ & $\begin{array}{l}\text { The degree of } \\
\text { how sociable or } \\
\text { unsociable, } \\
\text { sensitive or } \\
\text { insensitive, } \\
\text { personal and } \\
\text { impersonal a } \\
\text { solution is. }\end{array}$ & $\begin{array}{l}\text { Copresence, } \\
\text { sensitivity, } \\
\text { comprehensi } \\
\text { on }\end{array}$ & $\begin{array}{l}{[25 ; 29 ;} \\
30 ; 32 ; \\
38]\end{array}$ \\
\hline
\end{tabular}

\section{Method}

\subsection{Research setting and data collection}

We performed a web-based survey with IT user from companies to gather relevant information. The questionnaire was designed based on the existing IS literature, as shown above. Three IT managers and two postgraduate students from MIS field were consulted to proofread the questionnaire to ensure the validity and reliability of the measures. When designing the survey, we chose clear and concise items, intermixed items of different constructs on the questionnaire, and improved scale items consulting academic experts and IT managers, as well as we ensured anonymity to the respondents as manners to control method biases [39].

Next, the questionnaire was created in a free online tool to create and analyze surveys and was distributed by e-mail using a link. The sample consists of 286 employees of the administrative area from different companies. The survey had the support of the IT manager of all companies, who were in charge of sharing the link of the questionnaire among their employees. We offered the IT managers access to the survey results as a form of retribution.

\subsection{Measures}

The measures of the independent and dependent variables were obtained from prior studies (see Table 1). This study measured social influence and social presence using pre-validated scales. More specifically, social influence was based on [24] and [37] and social presence was operationalized from previous studies such as [25] and [30]. The social influence measure was composed of five items (e.g., "The manager of my business unit has been willing to use shadow IT" and "My co-workers frequently use shadow IT to perform their work tasks"). Similarly, social presence was measured using seven items (e.g., "I feel I am closer to the other person when I use shadow IT" and "I feel I am more easily understood when I use shadow IT at work").

The dependent variables Shadow IT Usage and Individual Impacts were based on previous studies about shadow IT, such as [8] and [3]. Shadow IT usage was measured using four items based on shadow IT literature (see the elements in Table 1). To ensure responders had the same understanding of shadow IT, we provided a definition and examples in the begging of the questionnaire.

In line with previous studies at individual level [40; 41], individual impacts were measured using five items (e.g., "I can solve problems faster when I use shadow IT at work" and "I can perform my work 
tasks quickly using shadow IT") and it was based on a subjective measure, that is, the IT user's perception on the impacts promoted by shadow IT in his/her work tasks. The items were proofread and validated by experts (interviews with IT managers and IS postgraduate students). All items of the variables were measured on a 7-point Likert scale, on which ' $1=$ strongly disagree' and ' $7=$ strongly agree'.

\section{Results}

This research used structural equation modelling with partial least squares (PLS) regression to test the research model. As commonly recommended [42], the study follows a two-step analysis to evaluation: (1) assessment of measurement model (outer model) and (2) estimation of structural model (inner model) and hypothesis tests.

\subsection{Assessment of the measurement model}

All constructs drew on a reflective measurement model in this study [42]. Table 2 reports Composite Reliability (CR), Average Variance Extracted (AVE) and Correlation matrix values. First, the analysis of internal consistency and the scale reliability were checked with Composite Reliability (CR). As can be seen, all CR and Alpha values are above the minimum threshold of 0.7 , demonstrating that all the constructs have high levels of internal consistency reliability [42].

Table 2. Composite reliability (CR), AVE and correlation matrix of constructs.

\begin{tabular}{|l|c|c|c|c|c|c|}
\hline Constructs & CR & AVE & SIU & SI & SP & II \\
\hline SITU & 0.800 & 0.501 & $\mathbf{0 . 7 0 8}$ & & & \\
\hline SI & 0.871 & 0.576 & 0.608 & $\mathbf{0 . 7 5 9}$ & & \\
\hline SP & 0.943 & 0.702 & 0.501 & 0.648 & $\mathbf{0 . 8 3 8}$ & \\
\hline II & 0.965 & 0.845 & 0.622 & 0.650 & 0.710 & $\mathbf{0 . 9 1 9}$ \\
\hline
\end{tabular}

Second, the outer loadings of the indicators and the average variance extracted (AVE) were used to establishing convergent validity. The outer loadings values ranged from 0.660 to 0.948 . Following [42] guidelines, we decided to retain the four reflective indicators below the threshold of 0.70 because their deletion does not lead to a considerable increase in the AVE and in the composite reliability values. The Average Variance Extracted (AVE) values should be higher than 0.50 [42]. Table 2 shows that all AVE values are higher than the acceptable threshold of 0.5 , demonstrating convergent validity for all constructs.

Third, we assessed the discriminant validity as shown in the correlation matrix in Table 2.
Considering the Fornell-Larcker criterion, which state that the AVE of each latent construct should be higher than the construct's highest squared correlation with any other latent construct, the discriminant validity was established for all constructs [42]. The study also applies the Heterotrait-Monotrait Ratio (HTMT) and the obtained values for the reflective variables were lower than the most conservative criterion of 0.85 [43], which reinforce the internal validity of the measurement model.

\subsection{Estimation of the structural model}

The estimation of the structural model involves examining the model's predictive capabilities and the relationships between the constructs. The results are based on the application of the bootstrapping procedure provided by SmartPLS and follow [42] guidelines for a minimum number of 5,000 bootstrap samples. First, we ensure that the results were not negatively affected by collinearity using Variance Inflation Factor (VIF) values.

Table 3 shows the hypothesis testing for relationships among constructs. The four paths are significant on the $\mathrm{p}<0.01$-level (sig. level $=1 \%$ ) and $\mathrm{p}<0.05$-level (sig. level $=5 \%$ ). The antecedent perceived social influence has a strong positive relationship with shadow IT usage $(\beta=0.488, p<$ 0.01 ), providing empirical support for hypothesis $\mathrm{H} 1$. The antecedent perceived social presence also has a positive relationship with shadow IT usage $(\beta=$ $0.185, \mathrm{p}<0.05)$, providing empirical support for hypothesis H2. In addition, the results show that shadow IT usage had a strong positive relationship with individual impacts $(\beta=0,284, \mathrm{p}<0.01)$, supporting the hypothesis H3.

Table 3. Hypothesis testing for relationships among constructs

\begin{tabular}{|l|l|c|c|c|c|c|c|}
\hline $\begin{array}{c}\text { Hypoth } \\
\text { esis }\end{array}$ & Path & $\begin{array}{c}\text { Direct } \\
\text { Effect }\end{array}$ & $\begin{array}{l}\text { Indirect } \\
\text { Effects }\end{array}$ & $\begin{array}{c}\text { Total } \\
\text { Effect } \\
\text { s }\end{array}$ & $\begin{array}{c}\text { t-Statistic } \\
\text { (a) }\end{array}$ & $\begin{array}{c}\mathrm{P} \\
\text { Value }\end{array}$ & Decision \\
\hline $\mathrm{H} 1 \mathrm{SI} \rightarrow$ SITU & 0.488 & - & 0.488 & $7.401^{* * *}$ & 0.000 & Supported \\
\hline $\mathrm{H} 1 \mathrm{a}$ & SI $\rightarrow$ SIT $\rightarrow$ II & 0.189 & 0.139 & 0.328 & $3.861 * * *$ & 0.000 & Supported \\
\hline $\mathrm{H} 2$ & SP $\rightarrow$ SITU & 0.185 & - & 0.185 & $2.906 * *$ & 0.004 & Supported \\
\hline $\mathrm{H} 2 \mathrm{a}$ & SP $\rightarrow$ SIT $\rightarrow$ II & 0.445 & 0.053 & 0.498 & $2.856^{* *}$ & 0.004 & Supported \\
\hline $\mathrm{H} 3$ & SITU $\rightarrow$ II & 0.284 & - & 0.284 & $5.530 * * *$ & 0.000 & Supported \\
\hline
\end{tabular}

(a) T-values for two-tailed test: ${ }^{*} 1.96$ (sig. level $=5 \%$ ); ${ }^{* *}$ t-value 2.57 (sig. level =1\%) [42].

The results also provide empirical support for the mediation hypotheses proposed. The mediation role of shadow IT on the relationship between social influence and individual impacts was supported with a significance level of $1 \%$, supporting hypothesis 
H1a. Shadow IT usage mediating the relationship between social presence and individual impacts was supported with a significance level of 5\%, supporting hypothesis H2a. Following Hair et al. [42] guidelines for mediation analysis regarding direct and indirect effects, the results show a complementary mediation of shadow IT usage on the relationship between social presence/social influence and individual impacts.

The $\mathrm{R}^{2}$ value of the dependent variables is a measure of the variance explained in each endogenous construct and the model's predictive accuracy. According to Cohen [44], $\mathrm{R}^{2}$ values for endogenous latent variables to social and behavioral sciences can be assessed as follows: $26 \%$ as substantial effect, $13 \%$ as moderate, and $2 \%$ as weak. The $\mathrm{R}^{2}$ value of the endogenous variables shadow IT usage and individual impacts are 0.390 and 0.616 , respectively. Thereby, the $\mathrm{R}^{2}$ values can be classified as substantial effect.

As an approximate measure of model fit, the study assessed the standardized root mean square residual (SRMR), assuming a cut-off value of 0.08 as the more adequate for PLS path models [45]. With a SRMR value of 0.07 , the model presented in this study shows an acceptable fit.

Finally, Stone-Geisser's $\mathrm{Q}^{2}$ measure was calculated. Running the blindfolding procedure with an omission distance of seven yielded, the crossvalidated redundancy values for the two endogenous variables were above zero (shadow IT usage: 0.183 and individual impacts: 0,516), supporting the model's predictive relevance [42].

\section{Discussion}

\subsection{Social influence and social presence as antecedents of Shadow IT usage}

The primary objective of this study was to investigate the relationship of perceived social influence and perceived social presence on shadow IT usage based on the assumption that social factors may drive individuals to use shadow IT. The results support the research model. We found that employees are influenced by their direct superiors and coworkers toward shadow IT usage, supporting social influence as an antecedent of shadow IT usage. This finding is consistent with the literature $[6 ; 22]$, which shows IT departments are no longer the only reference determining the technology adopted for use within companies. The increasing and maturing knowledge of users about technological solutions drive them to not only meet their own demands but also share their knowledge and experiences with coworkers.

Related to social influence, social presence was also supported as an antecedent of shadow IT usage by employees. Referents strongly influence individuals, and communication is a crucial factor in this social interaction process $[6 ; 27]$. As the literature posits, social presence is related to social interactions mediated by technology [30] and employees may change the social presence perceived by changing the technology according to their needs [34]. Employees frequently have to communicate and share information and files with people outside the organization, such as external partners and clients, which, for several reasons, is not always possible using the mandatory solutions (e.g., incompatible solution). The results show that employees decide to use technologies they perceive as providing greater social presence when using a shadow IT. Social presence is important in that sense because it provides efficient real-time communication and better collaboration at work $[10 ; 25]$.

\subsection{Shadow IT usage affecting employee's work performance}

This study also investigated the relationship of shadow IT usage and individual impacts related to employee's work performance. Consistent with previous research $[3 ; 12 ; 13]$, we found that, in general, shadow IT positively impacts work performance. Our results suggest that employees can perform their work tasks more quickly using shadow IT, increasing their productivity. The findings also show that shadow IT facilitates information sharing among employees. Thus, the present study confirms the significant and positive relationship of shadow IT usage on employee's performance, indicating that individual performance is a positive consequence of shadow IT usage.

\subsection{Social influence and social presence explaining the individual impacts of Shadow IT usage}

As discussed above, the literature indicates that shadow IT usage positively affects individual work performance $[8 ; 12]$. In addition to the greater availability of technology, users are also more familiar with and better informed regarding innovative solutions and are able to exploit them autonomously to meet their needs at work. The results of this investigation show that shadow IT usage has a strong positive relationship with 
individual impacts on employee work performance, increasing productivity and facilitating information sharing and problem-solving when performing work tasks. Furthermore, the relationship of social influence and social presence on shadow IT usage explain to some extent the individual impacts of shadow IT on employee work performance.

This study found that shadow IT can be a solution socially recognized among employees and mediate the relationship of perceived social influence and individual impacts. Humans are more influenced than they know or would like to be [46]. Consistent with the literature, the results of our study show that social influence is a critical factor for the use of work systems, including the use of unauthorized technologies at work [6]. The findings suggest whether the individual's referents (e.g., workmates and superiors) approve and support the use of a particular system, it may have several impacts including enhancement of the sense of membership [16] and user satisfaction [25], which positively affect work performance.

Similarly, shadow IT, often being collaborative technologies, can also mediate the relationship between social presence and individual impacts. Increasing the sense of social presence by using shadow IT can provide several benefits to employees in their work, such as permitting real-time communication, which facilitates information exchange and decision making [10; 25], enabling faster and better collaboration [8], and supporting knowledge sharing among employees [9]. All these individual impacts related to the greater perception of social presence promoted by shadow IT usage directly or indirectly enhance task performance [34].

\subsection{Theoretical and practical implications}

This study contributes to expanding knowledge on shadow IT at the individual level by performing an empirical investigation on the antecedents and consequences of employees' shadow IT usage. The findings from this research aid to explain some reason why individuals use shadow IT in the workplace instead of the mandatory system.

Regarding the consequences of shadow IT, the literature posits the necessity of empirically assessed positive and negative outcomes of using shadow IT [12]. We investigated the consequences of shadow IT usage in terms of individual impacts on employee's work performance and the results show that the use of shadow IT positively impacts individual performance. Thus, the findings here contribute to the discussion that, rather than a threat, shadow IT can be very valuable for organizations in terms of innovative solutions that enhance employee's performance.

The research here examined the phenomenon based on two widely used constructs from the IS field that was not applied in the shadow IT context yet. Previous research has suggested the relationship of social factors with user behaviour [7;25], including the relationship of shadow IT usage with social aspects $[8 ; 9 ; 10 ; 35]$. To the best of our knowledge, this study is the first to explicitly examine the phenomenon based on social aspects, which we found to be consistent with the evidence provided by the literature. The findings here validate the social presence and social influence as antecedents of shadow IT usage.

This study also provides some practical implications. Managers must pay attention to the fact that the main reason for the emergence of shadow IT is the complete or partial absence of adequate IT solutions that meet the employees' requirements [18]. Considering that shadow IT is used with the objective of increasing job performance [3], IT managers must better understand the causes and consequences of shadow IT in order to cope with this challenge, providing an adequate technology to employees, and formulating effective policies and strategies that either encourage or restrict such usage.

Considering the two factors analyzed here, we argue that managers must be aware of the social capabilities (e.g., communication) needed by business units and employees to efficiently perform their tasks. Several business units, as sales and marketing, have to interact with external partners and clients very often, being communication and collaboration capabilities central to their work performance. Thus, organizations should invest in technologies that enable users greater sense of social presence, such as instantaneous and dynamic communication with co-workers, external partners, and clients. With relation to social influence, IT managers must understand how social influence occurs and affects the behavior of IT user related to unauthorized use of technology [6]. Once social influence relies on communication and social interactions, IT managers could create initiatives and take actions to communicate and engage employees in the security policies, which is one of the primary concern related to shadow IT usage.

\section{Conclusion}

This empirical study revealed some important conclusions. The findings show that social factors play an essential role in the individual behavior 
toward shadow IT usage. Social influence and social presence are both antecedents of shadow IT usage, driving individuals and workgroups to use shadow IT within organizations. Moreover, these social factors explain to some extent the individual impacts of shadow IT on employee work performance.

In conclusion, shadow IT usage has a strong positive relationship with the social factors investigated here, which positively cause individual impacts on employee work performance. Shadow IT, thus, may be a collective solution used and socially recognized by workgroups, which can lead to optimized communication and collaboration among employees, teams or departments, including sharing the benefits of using these unauthorized systems.

This study has some limitations that can be motivations for further research. We used the constructs perceived social presence and social influence to analyze the behavior related shadow IT usage. Both theories could be deeply explored separately to understand the phenomenon.

Although in line with previous studies at individual level, measuring individual impacts based on a self-report can be also considered as a limitation. In addition, the research here has focus on collaborative shadow IT, which is unauthorized technology used by employees to collaborate and communicate at workplace $[8 ; 9 ; 10]$. However, there are other instances of shadow IT within companies that can be analyzed.

Finally, other theories can be useful to examine the social factors related to shadow IT. For instance, it would be valuable to apply a social constructionist perspective (e.g., Identities theory) that permits investigate personal aspects (e.g., individual values, beliefs and goals) and capture the nuances of the social environment [2].

\section{References}

[1] S. Turkle, Alone together: Why we expect more from technology and less from each other, Basic Books, New York, 2011.

[2] M. Carter, and V. Grover, "Me, my self, and I (T): conceptualizing information technology identity and its implications”, MIS Quarterly, 2015, 39(4).

[3] S. Haag, and A. Eckhardt, "Normalizing the ShadowsThe Role of Symbolic Models for Individuals' Shadow IT Usage”, Proceedings of ICIS, Auckland, 2014.

[4] Gartner, "Make the Best of Shadow IT", Available at: https://www.gartner.com/smarterwithgartner/make-thebest-of-shadow-it/, 2017, (Accessed: 16 November 2017).
[5] M. Silic, J.B. Barlow, and A. Back, "A new perspective on neutralization and deterrence: Predicting shadow IT usage", Information \& management. (in press), 2017, pp. 115.

[6] A. Eckhardt, S. Laumer, and N.T. Nguyen, "Social Influence in Technology Adoption Re-search-A Scientometric Study over two Decades Behavior", In Proceedings of the Diffusion Interest Group Technology (DIGIT) Workshop, St. Louis, USA, 2010.

[7] Y. Wang, D.B. Meister, and P.H. Gray, "Social influence and knowledge management systems use: Evidence from panel data", MIS Quarterly, 2013, 37(1).

[8] M. Silic, and A. Back, "Shadow IT-A view from behind the curtain", Computers \& Security, 2014, 45, pp. 274-283.

[9] G.L. Mallmann, A.C.G. Maçada, and M. Oliveira, "The influence of shadow IT usage on knowledge sharing: An exploratory study with IT users". Business Information Review, 2018, 35 (1), pp. 17-28.

[10] E. Shumarova, and P.A. Swatman, "Informal ecollaboration channels: Shedding light on 'shadow CIT",, In Proceedings of the LED, Paper 18, Bled, Slovenia, 2008.

[11] C.Y. Li, "Persuasive messages on information system acceptance: A theoretical extension of elaboration likelihood model and social influence theory". Computers in Human Behavior, 2013, 29(1), pp. 264-275.

[12] S. Haag, A. Eckhardt, and C. Bozoyan, "Are Shadow System Users the Better IS Users?-Insights of a Lab Experiment", In Proceedings of ICIS, Fort Worth, 2015.

[13] A.A.B. Györy, A. Cleven, F. Uebernickel, and W. Brenner, "Exploring the shadows: IT governance approaches to user-driven innovation", In Proceedings of the European Conference on Information Systems, Paper 222, Barcelona, Spain, 2012.

[14] D. Furstenau, H. Rothe, and M. Sandner, "Shadow Systems, Risk, and Shifting Power Relations in Organizations", Communications of the Association for Information Systems, 2017, 41(1), 3.

[15] S. Haag, and A. Eckhardt, "Shadow IT", Business \& Information Systems Engineering, 2017, pp. 1-5.

[16] W.H. Delone, and E.R. McLean, "The DeLone and McLean model of information systems success: a ten-year update", Journal of management information systems, 2003, 19(4), pp. 9-30.

[17] C. Rentrop, and S. Zimmermann, "Shadow IT. Management and Control of Unofficial IT", In Proceedings of the The Sixth International Conference on Digital Society, 2012, pp. 98-102. 
[18] M. Walterbusch, A. Fietz, and F. Teuteberg, "Missing cloud security awareness: investigating risk exposure in shadow IT", Journal of Enterprise Information Management, 2017, 30(4), pp. 644-665.

[19] S. Zimmermann, C. Rentrop, and C. Felden, "Managing Shadow IT Instances-A Method to Control Autonomous IT Solutions in the Business Departments", In Proceedings of the Twentieth AMCIS, Savannah, 2014.

[20] M. Huber, S. Zimmermann, C. Rentrop, and C. Felden, "Integration of Shadow IT Systems with Enterprise Systems - A Literature Review", In Proceedings of the Twenty First PACIS, Langkawi, 2017.

[21] S. Zimmermann, C. Rentrop, and C. Felden, "A Multiple Case Study on the Nature and Management of Shadow Information Technology", Journal of Information Systems, 2017, 31 (1), pp. 79-101.

[22] D. Furstenau, and H. Rothe, "Shadow IT systems: Discerning the good and the evil", In Proceedings of the Twenty-Second European Conference on Information Systems, Tel Aviv, Israel, 2014.

[23] D. Jones, S. Behrens, K. Jamieson, and E. Tansley, "The rise and fall of a shadow system: Lessons for enterprise system implementation", In Proceedings of the ACIS (Australasian), 2004

[24] V. Venkatesh, M.G. Morris, G.B. Davis, and F.D. Davis, "User Acceptance of Information Technology: Toward a Unified View", MIS Quarterly, 2003, 27(3), pp. 425-478.

[25] S.O. Ogara, C.E. Koh, and V.R. Prybutok, "Investigating factors affecting social presence and user satisfaction with mobile instant messaging", Computers in Human Behavior, 2014, 36, pp. 453-459.

[26] C. Jiang, W. Zhao, X. Sun, K. Zhang, R. Zheng, and W. Qu, "The effects of the self and social identity on the intention to microblog: An extension of the theory of planned behavior", Computers in Human Behavior, 2016, 64, pp. 754-759.

[27] H.C. Kelman, "Compliance, identification, and internalization three processes of attitude change", Journal of conflict resolution, 1958, 2(1), pp. 51-60.

[28] Y. Lee, J. Lee, and Z. Lee, "Social influence on technology acceptance behavior: self-identity theory perspective", ACM SIGMIS Database, 2006, 37(2-3), pp. 60-75.

[29] F. Biocca, and C. Harms, "Defining and measuring social presence: Contribution to the net-worked minds theory and measure", In Proceedings of the PRESENCE, 2002, pp. 7-36.
[30] F. Biocca, C. Harms, and J.K. Burgoon, "Toward a more robust theory and measure of social presence: Review and suggested criteria”, Presence, 2003, 12(5), pp. 456-480.

[31] J. Short, E. Williams, and B. Christie, The social psychology of telecommunications, John Wiley \& Sons, London, 1976.

[32] B.E. Mennecke, J.L. Triplett, L.M. Hassall, Z.J. Conde, and R. Heer, "An examination of a theory of embodied social presence in virtual worlds", Decision Sciences, 2011, 42(2), pp. 413-450.

[33] P. Wang, "Chasing the hottest IT: effects of information technology fashion on organizations", MIS quarterly, 2010, 34(1), pp. 63-85.

[34] S. Parameswaran, and R. Kishore, "A Social Presence Model of Task Performance: A Meta-Analytic Structural Equation Model", In Proceeding of the Twenty-third Americas Conference on Information Systems, Boston, USA, 2017.

[35] M. Steinhüser, L. Waizenegger, V. Vodanovich, and A. Richter, "Knowledge Management without Management - Shadow IT in Knowledge-intense Manufacturing Practices", In Proceedings of the 25th European Conference on Information Systems, Guimarães, Portugal, 2017.

[36] S. Haag, "Appearance of Dark Clouds?-An Empirical Analysis of Users' Shadow Sourcing of Cloud Services", Wirtschaftsinformatik, 2015, pp. 1438-1452.

[37] S.O. Ogara, "Design for Social Presence and Exploring Its Mediating Effect in Mobile Data Communication Services", (Doctoral dissertation, University of North Texas), 2011.

[38] K.L. Nowak, and F. Biocca, "The effect of the agency and anthropomorphism on users' sense of telepresence, copresence, and social presence in virtual environments", Presence: Tele-operators and Virtual Environments, 2003, 12(5), pp. 481-494.

[39] P.M. Podsakoff, S.B. MacKenzie, J.Y. Lee, and N.P. Podsakoff, "Common method biases in behavioral research: a critical review of the literature and recommended remedies", Journal of applied psychology, 2003, 88(5), pp. 879.

[40] D.L. Goodhue, and R.L. Thompson, "Task-technology fit and individual performance", MIS quarterly, 1995, pp. 213-236.

[41] S. Mohammadyari, and H. Singh, "Understanding the effect of e-learning on individual performance: The role of digital literacy", Computers \& Education, 2015, 82, pp. 1125. 